\title{
A Systematic Understanding of Participation of Kachari Tribe Eri Silkworm Rearers' in Jorhat District of Assam, India
}

\author{
Chowcin Borsali Buragohain and Monimala Saikia* \\ Department of Sericulture, College of Agriculture, Assam Agricultural University, \\ Jorhat, Assam, India \\ *Corresponding author
}

\section{A B S T R A C T}

\section{Keywords \\ Sericulture, Eri culture, Kachari tribe, Participation of men and women \\ Article Info \\ Accepted: 10 July 2020 Available Online: 10 August 2020}

The present study was conducted among the eri rearers of Kachari tribe in the Jorhat district of Assam with a sample size of 120 respondents. Participation of women was found to be higher in eri culture activities. The study revealed that participation of women in nursery preparation (23.75\%) and main field preparation $(14.76 \%)$ was low against men. But, in rearing of eri silkworm and marketing (81.67\%) and in post cocoon technology (93.33\%) the participation of women was high against men. Ericulture has proved to be an excellent vocation for the development of tribal and rural women of Assam. For betterment of the eri rearers and for generating livelihood in eri culture, both skilled and unskilled tribal and small farmers should be encouraged by providing facilities and training.

\section{Introduction}

Sericulture, or silk farming, is the cultivation or rearing of silkworms to produce silk. Sericulture with its high employment potentiality and more income generation has been found as one of the major modes of rural development (Roy and Sarkar, 2015). Sericulture is considered as one of the promising rural industries of India as it is a high employment potential women friendly occupation ideal for weaker section of the society with low investment and high returns and can able to provide vibrancy to village economy by satisfying the equity concern
(Anon., 2019). Sericulture comprises rearing of four types of silkworm viz., mulberry, eri, muga and tasar. The north-east region of India occupies a unique position in producing all the commercial varieties of silk. The northeast India is the easternmost region of India and it represents both the geographic and political administrative division of the country. North eastern region of India is endowed with huge untapped natural resources and can very well sustain its populace. This region lies between $20-29^{\circ} \mathrm{N}$ latitude and $90-97^{\circ} \mathrm{E}$ longitude and spreads over an area of 2,62,230 sq. km. The humid climate of Assam is very favorable for the 
culture of eri silkworm. Assam is the leading producer of eri silk. Among all the silks found in Assam, eri silk is particularly fascinating, as it is processed without killing the silkworm and thus, often referred as 'Ahimsa silk'. Eri silk is also known as 'endi' or 'errandi' in India and is considered as the poor man's silk. Eri culture is one of the traditional practices sustaining amidst the tribal communities inhabitant in the rural areas in the north-east region of India especially in Assam and the people are considering it as a subsidiary occupational venture since time immemorial (Mech and Ahmed, 2012). Sericulture occupies a place of pride in the rural economy and tribal sectors by being the only cash crop that guarantees attractive returns in a short period of time (Ganie et al., 2018). It also provides jobs and income resources for rapidly increasing population engaged in farming as well as to unemployed youths and women. All family members, irrespective of gender and age, can contribute to the success of sericulture and, in this sense; it can be considered a home-based industry (Kasi, 2013). Farmers can earn additional income from sericulture industry when they remain free from any agricultural activities. Thousands of families in Assam have been engaged directly or indirectly in various ericulture activities like sowing of seeds, plantation of host plants, maintenance of plants, plucking of leaves from the planted and wildly grown trees, feeding and rearing of silkworm upto cocoon stage, spinning of yarn, weaving of fabrics, marketing of cocoons and cloth etc. In Assam, ericulture is mainly practiced by the Bodos, Kacharis, Misings, Garos, Ahoms and Karbis. It is associated with their socio-economic and cultural life. Therefore, number of families engaged in ericulture is high in those districts where number of tribal people is high (Kakoti, 2012). Sericulture is one of the secondary sources of income of the Thengal Kacharis of Assam. They rear eri and muga at home in villages. The silk products are used for themselves and are sold in the market at a very small scale. The women folk are expert in making clothes in their handloom (Dutta, 2010). Eri rearing in Jorhat district has been traditionally practiced. Ericulture has been acting as antidotes to the problem of unemployment and reduction in poverty in the district as well as Assam for a long period of time. Though rearing of cocoon alone does not contribute much to the family income, the spinning and weaving activities along with the rearing contribute significantly to the employment and income of those families (De and Das, 2007). Sericulture is the only one cash crop in agriculture sector that gives returns within thirty days. It can provide income throughout the year. Therefore, sericulture related policies should be made more women oriented and rural women should be encouraged by government and non-governmental organizations for rapid development of this agro-based cottage industry as well as rural India (Saikia and Ghosh, 2018). The net income generated by the families in spinning and weaving includes their imputed wages and profits together. Hence, the proposed study is aimed to visualize the participation of the eri silkworm rearers from Kachari tribe engaged in different activities of eri culture in Jorhat district of Assam.

\section{Materials and Methods}

Jorhat is purposively selected for the present study so as to understand and study the involvement and participation of eri rearers of the Kachari tribe in eri culture so that their existing livelihoods can be upgraded and made sustainable. The area of investigation has been depicted in Fig.1. Three villages viz. Lohong Gaon, Kachukhat Gaon and Sonowal Gaon were selected based on the concentration of eri rearers. To obtain information and response for the present 
study, 40 respondents (out of which 20 were male and 20 were female) were selected randomly from each of the selected villages. Thus, the total number of respondents was 120.

Primary data on participatory profiles in host plant nursery preparation, cultural operations, rearing of silkworm and marketing, post cocoon technology in ericulture etc. were collected randomly from 120 household actively associated in eri culture through personal contact method using pre structured interview schedule. The interview schedule employed in the study consisted of both structured and open ended questions. Simple percentage was taken to interpret the findings in case of participation of men and women in different activities involved in eri culture.

\section{Results and Discussion}

Participation of men and women in nursery preparation in eri culture

The data presented in the Table 1 indicates that in some light activities of nursery preparation, few of the women participated occasionally. These are predominantly male activities. It has been recorded that $36.67 \%$ women participated each in seed collection and sowing and also in watering and weeding.
The study showed that out of the total respondents involved in eri culture, average participation of women in nursery preparation was $23.75 \%$ against participation of $83.33 \%$ men.

\section{Participation of men and women in main field preparation, transplanting and cultural operations in eri culture}

It can be observed that participation of men was significantly higher against women in the activities in main field preparation, transplanting and cultural operations (Table 2). Selection and preparation of land, pit digging, manuring at pit, application of fertilizer, protection of plantation from disease and pest are hard and need both physical strength and skills.

The women do not play significant role in these activities. However, few women participated in some light activities like transplanting of seedling and watering and weeding etc. It was recorded that $23.33 \%$ women participated in transplanting of seedling and $40.00 \%$ women participated in watering and weeding of plantation. Average participation of women in main field preparation, transplanting and cultural operations in eri culture was $14.76 \%$ against participation of $79.52 \%$ men.

Table.1 Participation of men and women in nursery preparation in eri culture $(\mathrm{N}=120)$

\begin{tabular}{|c|c|c|c|}
\hline Sl. No. & Activities & Men & Women \\
\hline $\mathbf{1}$ & Seed bed preparation & $48(80.00)$ & $1(1.67)$ \\
\hline $\mathbf{2}$ & Seed collection and sowing & $52(86.67)$ & $22(36.67)$ \\
\hline $\mathbf{3}$ & Watering and weeding & $52(86.67)$ & $22(36.67)$ \\
\hline $\mathbf{4}$ & Transportation of seedling & $48(80.00)$ & $12(20.00)$ \\
\hline Average & & $50.00(83.33)$ & $14.25(23.75)$ \\
\hline
\end{tabular}

Figure in parenthesis indicate percentage 
Table.2 Participation of men and women in main field preparation, transplanting and cultural operations in eri culture $(\mathrm{N}=120)$

\begin{tabular}{|c|c|c|c|}
\hline Sl. No. & Activities & Men & Women \\
\hline $\mathbf{1}$ & Selection and preparation of land & $48(80.00)$ & $2(3.33)$ \\
\hline $\mathbf{2}$ & Pit digging & $43(71.67)$ & $1(1.67)$ \\
\hline $\mathbf{3}$ & Manuring at pit & $46(76.67)$ & $4(6.67)$ \\
\hline $\mathbf{4}$ & Transplanting of seedling & $54(90.00)$ & $14(23.33)$ \\
\hline $\mathbf{5}$ & Watering and weeding & $54(90.00)$ & $24(40.00)$ \\
\hline $\mathbf{6}$ & Application of fertilizer & $41(68.33)$ & $6(10.00)$ \\
\hline $\mathbf{7}$ & Protection of plantation from & $48(80.00)$ & $11(18.33)$ \\
\hline & disease and pest & & \\
\hline Average & & $47.71(79.52)$ & $8.85(14.76)$ \\
\hline
\end{tabular}

Figure in parenthesis indicate percentage

Table.3 Participation of men and women in rearing of eri silkworm and marketing $(\mathrm{N}=120)$

\begin{tabular}{|c|c|c|c|}
\hline Sl. No. & Activities & Men & Women \\
\hline $\mathbf{1}$ & Assessment of dfls/ layings to be brushed & $38(63.33)$ & $23(38.33)$ \\
\hline $\mathbf{2}$ & Disinfection of rearing appliances and & $24(40.00)$ & $49(81.67)$ \\
\hline $\mathbf{3}$ & rearing house & & $60(100.00)$ \\
\hline $\mathbf{4}$ & Transfer of larvae & $48(80.00)$ & $60(100.00)$ \\
\hline $\mathbf{5}$ & Early and late stage rearing & $48(80.00)$ & $21(35.00)$ \\
\hline $\mathbf{6}$ & Preparation of mountage & $56(93.33)$ & $60(100.00)$ \\
\hline $\mathbf{7}$ & Collection of matured larvae & $50(83.33)$ & $60(100.00)$ \\
\hline $\mathbf{8}$ & Harvesting of cocoons & $49(81.67)$ & $50(66.67)$ \\
\hline $\mathbf{9}$ & Disease and pest control & $50(83.33)$ & $59(96.67)$ \\
\hline $\mathbf{1 0}$ & Marketing of cocoons & $49(81.67)$ & $49.33)$ \\
\hline Average & Marketing of pupae & $47.10(78.50)$ & $49.00(81.67)$ \\
\hline
\end{tabular}

Figure in parenthesis indicate percentage

Table.4 Participation of men and women in post cocoon technology in ericulture $(\mathrm{N}=120)$

\begin{tabular}{|c|c|c|c|}
\hline Sl. No. & Activities & Men & Women \\
\hline $\mathbf{1}$ & Selection of cocoons & $59(98.33)$ & $60(100.00)$ \\
\hline $\mathbf{2}$ & Storing of cocoons & $51(85.00)$ & $59(98.33)$ \\
\hline $\mathbf{3}$ & Cooking of cocoons & $9(15.00)$ & $56(93.33)$ \\
\hline $\mathbf{4}$ & Spinning of silk & $6(10.00)$ & $50(83.33)$ \\
\hline $\mathbf{5}$ & Preparation of hank & $23(38.33)$ & $55(91.67)$ \\
\hline Average & & $29.60(49.33)$ & $56.00(93.33)$ \\
\hline
\end{tabular}

Figure in parenthesis indicate percentage 
Fig.1 Map of Jorhat district

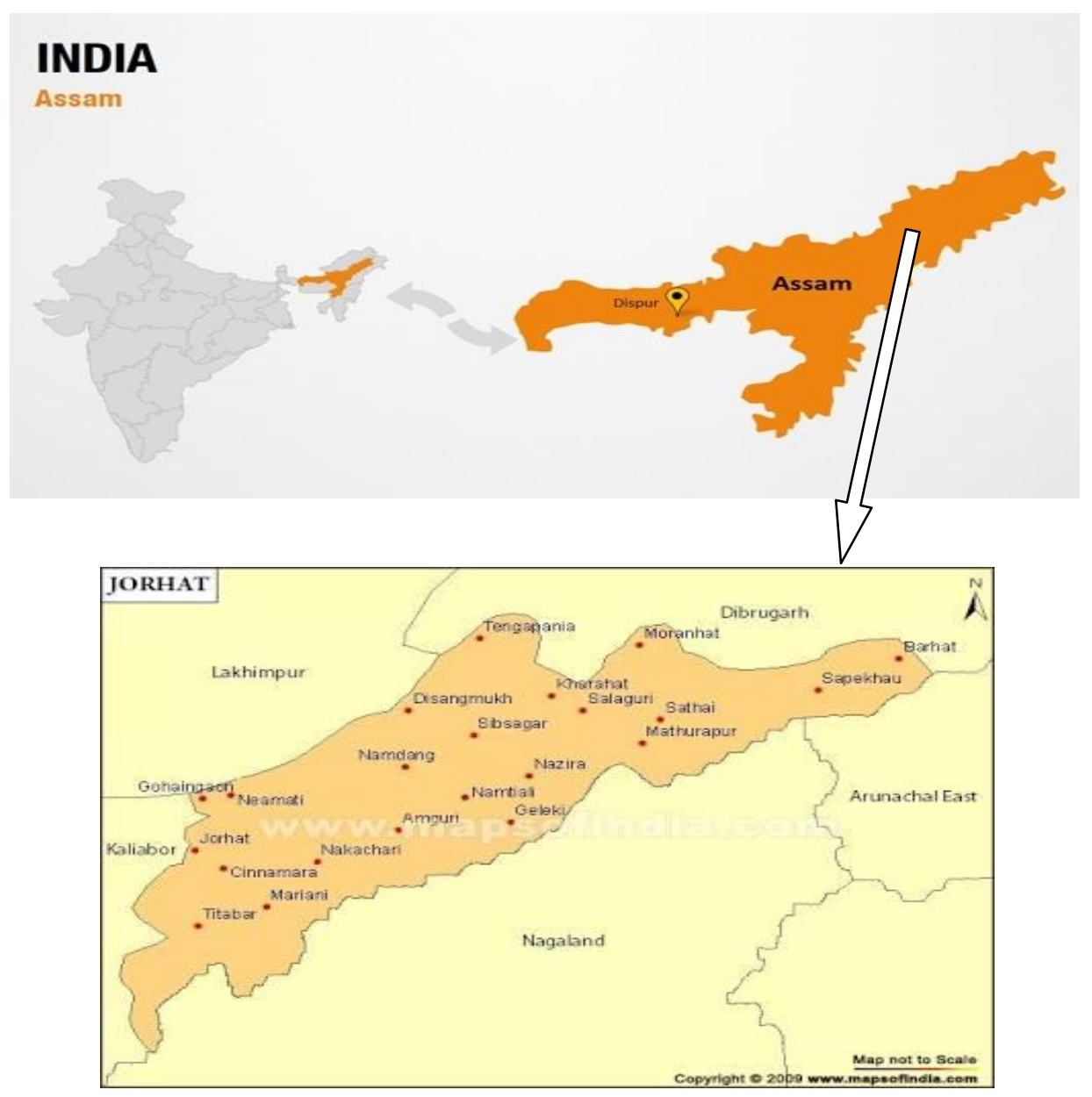

Participation of men and women in rearing of eri silkworm and marketing

Average participation of women in rearing of eri silkworm and marketing was $81.67 \%$ against participation of $78.50 \%$ men. Some of the practices that they follow are mentioned in Table 3. In comparison to men, women respondents were found to participate more in the activities like disinfection of rearing appliances and rearing house (81.67\%), transfer of larvae $(100.00 \%)$, early and late stage rearing $(100.00 \%)$, collection of matured larvae $(100.00 \%)$, harvesting of cocoons (100.00\%), marketing of cocoons $(96.67 \%)$ and marketing of pupae $(98.33 \%)$.
Participation of men and women in post cocoon technology in ericulture

Data presented in Table 4 indicated that average participation of women in selection of cocoons, storing of cocoons, cooking of cocoons, spinning of silk and preparation of hank was $93.33 \%$ against participation of $49.33 \%$ men. Participation of women in post cocoon technology in ericulture was significantly higher against men. It has been recorded that participation of women was $100.00 \%$ in selection of cocoons, $98.33 \%$ in storing of cocoons, $93.33 \%$ in cooking of cocoons, $83.33 \%$ in spinning of silk and $91.67 \%$ in preparation of hank. 
Setty et al., (2019) reported that 87.82 per cent of the Tasar rearers of Jharkhand state were from tribal community (ST). In Assam $60 \%$ tribal women attend all the activities of eri silkworm rearing such as leaf plucking, feeding of worms, bed cleaning, collection of dry leaves for spinning and lastly harvesting (Mech and Ahmed, 2012). Ericulture has proved to be an excellent vocation for the development of tribal and rural women of Assam. Agriculture is practiced as the primary occupation by the people of Assam. Sericulture is a secondary occupation and mainly carried out when agriculture practices are over or light. Mainly women perform sericulture practices as they tend to stay at home and can manage the required time for rearing of silkworms besides their household activities. And thus they contribute. Raveesha et al., mentioned that involvement of women is high in different activities of Mulberry cultivation in Karnataka except those activities which involve going out from their homes. Men are engaged in their respective occupations and contribute less time than women in sericulture practices. However, men perform all the operations that require more physical strength and skill. Both in agriculture and sericulture operations, women are seen to contribute more in the light activities may be because it requires less strength and skill.

In conclusion almost all the activities in Sericulture are carried out by women, except some which are shared along with men. However, there are certain jobs like weeding, leaf harvest, rearing of silkworm, silk reeling which are exclusive monopoly of women (Sarkar et al., 2017).

Based on the findings of the present study, it may be concluded that women are more involved in eri silkworm culture among the Kachari tribe people. Although their participation is low in nursery preparation and main field preparation but high in eri silkworm rearing, marketing and post cocoon technology activities. The tasar silk industry has acquired a big role in improving tribal socio-economic condition besides generating substantial rural employment (Goel et al., 1993; Suryanarayana et al., 2005, Rao, 2007). Ericulture has also immense potential in generating livelihood to the tribal and rural women as income is generated within a month and round the year which can be utilized more profitably for the social and economic development of the family. Rural and marginal farmers including tribal people and women should be encouraged to take eri culture as well as other sericulture activities for the development of rural India.

\section{References}

Anonymous

(2019). http://www.csb.gov.in/silksericulture/se riculture/ retrieved on $5^{\text {th }}$ July, 2019.

Anonymous (2020a) https://images.app.goo.gl/EqQ3wrZwa nKiJT8x6 retrieved on 13th July, 2020.

Anonymous (2020b) https://images.app.goo.gl/fw7GyBkBB PHfvj2L6 retrieved on 13th July, 2020.

De, U.K. and Das, M. (2007). Ericulture as a remedy of rural poverty in Assam: a micro level study in Barpeta district. MPRA Paper 6291, University Library of Munich, Germany, pp. 3.

Dutta, K. (2010). Ethnicity and folklore a study among the Thengal Kacharis of Assam. Thesis submitted to Gauhati University, Assam.

Ganie, N.A.; Dar, K.A.; Khan, I.L.; Sharma, R.K. and Sahaf, K.A. (2018). Sericulture- a viable option for sustainable livelihood and employment generation for rural population of $\mathbf{J} \&$ K. Global Journal of Bio-Science and Biotechnology, 7(1): 200-203.

Goel, A.K.; Brahmachari, B.N.; Thandapani, 
M. and Thangavelu, K.(1993). Socioeconomic study of tasar culture. Indian Silk, 31(12): 38-42

Kakoti, R.K. (2012). Sericulture as well as ericulture as a source of employment and income. Basic, Applied \& Social Sciences, 2: 370-37.

Kasi, E. (2013). Role of women in sericulture and community development: a study from a South Indian village. Sage Open, (July-September): 1-11.

Mech, D. and Ahmed, S.A. (2012). Participatory profiles of women in eri culture in Assam state of India. European Journal of Applied Sciences, 4(4): 177-181.

Rao, K.M. (2007). Tasar culture and forest policy constraints and guidelines. Indian Silk, 45(10): 14-18.

Raveesha, S.; Kumar, K.A. and Bai, D.S. (2016). A socio-economic analysis of women's participation in sericulture. Advance Research Journal of Social Science, 7(1): 55-61.

Roy, P. and Sarkar, R. (2015). Work Participation and Income Generation from Sericulture: A Case Study of
Alomtola Village of Kaliachak-II Block in Malda District, West Bengal. Social and Economic Geography, 1(1): 31-36.

Saikia, M. and Ghosh, K. (2018). Involvement and contribution of women in eri culture activities in Jorhat district of Assam. Journal of Entomology and Zoology Studies, 6(6): 391-395.

Sarkar, K.; Majumdar, M. and Ghosh, A. (2017). Critical Analysis on Role of Women in Sericulture Industry. International Journal of Social Science, 6(3): 211-222.

Setty, H.H.N.; Gopal, L. and Chinnaswamy, K.P. (2019). Empowerment of tribal communities through sericulture programmes in Jharkhand State. IJRDO - Journal of Social Science and Humanities Research, 4(2): 23-30.

Suryanarayana,N. and Srivastava, A.K. (2005). Monograph on Tropical Tasar Silkworm. Central Tasar Research and Training Institute, Central Silk Board, Ranchi, India, pp: 1-87

\section{How to cite this article:}

Chowcin Borsali Buragohain and Monimala Saikia. 2020. A Systematic Understanding of Participation of Kachari Tribe Eri Silkworm Rearers' in Jorhat District of Assam, India. Int.J.Curr.Microbiol.App.Sci. 9(08): 352-358. doi: https://doi.org/10.20546/ijcmas.2020.908.041 